\title{
Lithosphere-asthenosphere Boundary Beneath the Sea of Japan From Transdimensional Inversion of S Receiver Functions
}

\section{Takeshi Akuhara ( $\square$ akuhara@eri.u-tokyo.ac.jp )}

The University of Tokyo: Tokyo Daigaku https://orcid.org/0000-0002-6129-8459

\section{Kazuo Nakahigashi}

Tokyo University of Marine Science and Technology

\section{Masanao Shinohara}

University of Tokyo: Tokyo Daigaku

\section{Tomoaki Yamada}

University of Tokyo: Tokyo Daigaku

\section{Hajime Shiobara}

University of Tokyo: Tokyo Daigaku

\section{Yusuke Yamashita}

Kyoto University: Kyoto Daigaku

Kimihiro Mochizuki

University of Tokyo: Tokyo Daigaku

\section{Kenji Uehira}

National Research Institute for Earth Science and Disaster Resilience

\section{Full paper}

Keywords: Back-arc basin, Lithosphere-asthenosphere boundary, Sea of Japan, S-receiver function, Transdimensional inversion, Ocean-bottom seismometer

Posted Date: May 18th, 2021

DOl: https://doi.org/10.21203/rs.3.rs-523351/v1

License: (c) (i) This work is licensed under a Creative Commons Attribution 4.0 International License. Read Full License 
1 Lithosphere-asthenosphere boundary beneath the Sea of Japan from

\section{2 transdimensional inversion of $\mathrm{S}$ receiver functions}

$3 \quad$ Takeshi Akuhara ${ }^{1}$, akuhara@eri.u-tokyo.ac.jp

$4 \quad$ Kazuo Nakahigashi², knakah0@kaiyodai.ac.jp

5 Masanao Shinohara ${ }^{1}$, mshino@eri.u-tokyo.ac.jp

6 Tomoaki Yamada ${ }^{1}$, yamada@eri.u-tokyo.ac.jp

$7 \quad$ Hajime Shiobara ${ }^{1}$, shio@eri.u-tokyo.ac.jp

$8 \quad$ Yusuke Yamashita ${ }^{3}$, yamac@rcep.dpri.kyoto-u.ac.jp

$9 \quad$ Kimihiro Mochizuki ${ }^{1}$, kimi@eri.u-tokyo.ac.jp

10 Kenji Uehira ${ }^{4}$, uehira@bosai.go.jp

$11{ }^{1}$ Earthquake Research Institute, The University of Tokyo, 1-1-1, Yayoi, Bunkyo-ku,

12 Tokyo 113-0032, Japan

$13{ }^{2}$ Department of Marine Resources and Energy, Tokyo University of Marine Science and

14 Technology, 4-5-7, Konan, Minato-ku, Tokyo 108-8477, Japan

$15{ }^{3}$ Miyazaki Observatory, Research Center for Earthquake Prediction, Disaster Prevention

16 Research Institute, Kyoto University, 3884, Kaeda, Miyazaki 889-2161, Japan

$17{ }^{4}$ National Research Institute for Earth Science and Disaster Resilience, 3-1, Tennodai,

18 Tsukuba-shi, Ibaraki 305-0006, Japan 
19 Corresponding author: Takeshi Akuhara 


\section{Abstract}

22 The evolution history of the Sea of Japan back-arc basin remains under debate,

23 involving the opening of sub-basins such as the Japan and Yamato Basins. Detailed

24 knowledge of the lithospheric structure will provide the key to understanding tectonic

25 history. This study identifies the lithosphere-asthenosphere boundary (LAB) beneath

26 the Sea of Japan back-arc basin using S-receiver functions (S-RFs). The study area,

27 including the Japan and Yamato Basins, has been instrumented with broadband ocean-

28 bottom seismometers (OBSs). S-RFs from these OBSs show negative Sp phases

29 preceding the direct S arrivals, suggesting the LAB. The S-RFs also show abnormally

30 reduced amplitudes. For further qualitative interpretation of these findings, we conduct

31 transdimensional Bayesian inversion for S-wave velocity models. This less-subjective

32 Bayesian approach clarifies that the low-velocity seafloor sediments and damped

33 deconvolution contribute to the amplitude reduction, illuminating the necessity of such

34 considerations for similar receiver function works. Inverted velocity structures show a

35 sharp velocity decrease at the mantle depths, which we consider the LAB. The obtained

36 LAB depths vary among sites: $\sim 45 \mathrm{~km}$ beneath the Japan and Yamato Basins and $\sim 70$

$37 \mathrm{~km}$ beneath the Yamato Rise, a bathymetric high between the two basins. The thick

38 lithosphere beneath the Yamato Rise most likely reflects its continental origin. However, 
39 the thickness is still thin compared to that of eastern Asia, suggesting lithosphere

40 extension by rifting. Notably, the Japan and Yamato Basins show a comparable

41 lithospheric thickness, although the crustal thickness beneath the Yamato Basin is

42 known to be anomalously thick. This consistency in the lithospheric thickness implies

43 that both basins undergo similar back-arc opening processes.

44

\section{$45 \quad$ Keywords}

46 Back-arc basin

47 Lithosphere-asthenosphere boundary

48 Sea of Japan

49 S-receiver function

50 Transdimensional inversion

51 Ocean-bottom seismometer 


\section{Background}

53 The Sea of Japan,located between the Japanese island-arc and Asia's eastern margin,

54 hosts three sub-basins (Japan, Yamato, and Tsushima Basins) and a topographic high

55 (the Yamato Rise) (Figure 1). The sea evolved through rifting and back-arc spreading,

56 which have isolated Japanese Islands from Asia's continent. The rifting is likely to have

57 begun at $\sim 23 \mathrm{Ma}$, and the whole opening process ceases at $\sim 15 \mathrm{Ma}$ (Martin 2011; Van

58 Horne et al. 2017), where clues come from various disciplines including radiometric

59 dating for core samples (Tamaki et al. 1990), paleomagnetism from rocks (Otofuji et al.

601985 ) and the seafloor (Seama and Isezaki 1990), dike, vein, and fault orientations (Sato

61 1994), and migration of a volcanic front (Tatsumi et al. 1989). However, limited

62 spatiotemporal resolution of these data makes the comprehensive understanding of the

63 evolution process challenging. A major consensus is that back-arc spreading contributes

64 to the formation of the Japan Basin, as is implied from the lineation pattern in the

65 seafloor magnetic anomaly. In contrast, the formation processes of the Yamato and

66 Tsushima basins are still open questions because of unclear magnetic anomaly and

67 anomalous features of the crust, as introduced below.

68 Many active-source seismic surveys have revealed crustal structure at the Sea of Japan

69 (Hirata et al. 1989; Kurashimo et al. 1996; Sato et al. 2006, 2018; Nakahigashi et al. 
70 2013) and also have provided unique constraints on the evolution process. At the Japan

71 Basin, the crust has a typical thickness of $\sim 7 \mathrm{~km}$ for the oceanic crust, whereas the crust

72 at the Yamato and Tsushima Basins is anomalously thick with a thickness of $\sim 15 \mathrm{~km}$.

73 Although the origin is still puzzling, their relatively high $\mathrm{P}$-wave velocities (Vp)

74 resemble typical oceanic crusts than continental crusts (Sato et al. 2018). Hirata et al.

75 (1989) has attributed the cause of this thickened crust to an excess magma supply after

76 the termination of the seafloor spreading, which follows the abrupt tectonic reversal to

77 the compressional field at $\sim 15 \mathrm{Ma}$ (Sato 1994). The Yamato Rise is a region with the

78 thickest crusts in the sea with a thickness of $\sim 25 \mathrm{~km}$ (Kurashimo et al. 1996; Kulinich

79 and Valitov 2011). The lower Vp than the surrounding basins suggests that the rise is an

80 extended, isolated continental crust (Kurashimo et al. 1996; Sato et al. 2018).

81 Revealing the lithospheric thickness, which is the first-order feature of the lithosphere

82 structure, also benefits for better understanding the tectonics. Surface wave analyses

83 have played that role for the Sea of Japan. The early studies by Abe \& Kanamori (1970)

84 and Evans et al. (1978) have estimated the averaged lithospheric thickness beneath the

85 Sea of Japan to be $\sim 30-40 \mathrm{~km}$, using a few propagation paths crossing the sea of Japan.

86 Modern surface wave tomography analyses with teleseismic sources (Yoshizawa et al.

87 2010) and ambient noise (Zheng et al. 2011) have constructed 3D S-wave velocity (Vs) 
88 models beneath the Sea of Japan. Both models identify a higher velocity of the

89 lithosphere and a lower velocity of the asthenosphere with the transition occurring at

$90 \sim 50-70 \mathrm{~km}$ depth. However, the limited spatial resolution prohibits the precise

91 determination of the lithosphere-asthenosphere boundary (LAB) depth, which is

92 inherent to surface wave studies.

93 The S-receiver function (S-RF) analysis (e.g., Yuan et al. 2006) can reveal lithospheric

94 thicknesses at a high spatial resolution by detecting Sp converted phases at the LAB.

95 The method is advantageous over P receiver functions since the Sp converted phases are

96 free from interferences by free-surface multiples. Because of its promised feature,

97 numerous studies have employed this method to detect LAB (Kumar et al. 2005;

98 Rychert et al. 2005; Lekic et al. 2011; Zhang et al. 2014; Hopper et al. 2020), and some

99 of them have applied the method to the ocean-bottom environment (Kawakatsu et al.

100 2009; Kumar et al. 2011; Rychert et al. 2018, 2021; Mark et al. 2021). However, the

101 effects of unconsolidated sediments at the ocean bottom on S-RF waveforms has not

102 been fully understood yet, which is another focus of this paper.

103 This study aims to constrain the LAB depths by applying the S-RF method to seven

104 ocean-bottom seismometers (OBSs) deployed at the Japan and Yamato Basins and the

105 Yamato Rise. We perform transdimensional inversion to interpret S-RFs as Vs structure 
106 for three selected stations with good quality. Results indicate a thin lithosphere beneath

107 the basins and a thick lithosphere beneath the Yamato Rise. Based on these results, we

108 discuss the evolution process of the Sea of Japan.

109

110 Data

111 This study uses seismic waveform data from OBSs deployed at seven sites at the Sea of

112 Japan: JS2, YMB3, and YMB4 located at the Yamato Basin; JPB4, JPB5, and JPB6 at

113 the Japan Basin; and JS4 at the Yamato Rise (Figure 1). The observation periods differ

114 from place to place. The intended observation period was one year or more for each site,

115 but instrument malfunction limits data the lengths for JPB5 and JS2 to less than one

116 year. The longest observation period is about two years. Table 1 summarizes the

117 observation data analyzed by this study.

118 All seismometers mentioned above contain Gularp CMG-3T broadband sensors (Güralp

119 Systems Ltd.) with a flat response at periods shorter than 360 s. Additionally, the series

120 of temporary seismic observations involve deployments of short-period OBSs with a

121 natural frequency of $1 \mathrm{~Hz}$. Unfortunately, these short-period sensors prove to be

122 ineffective in detecting clear onsets on teleseismic S waveforms. Thus, the present study

123 only focuses on the data from the broadband OBSs. The orientations of horizontal 
124 sensors are unknown because OBSs descend freely to the ocean bottom by gravity. The

125 sensor orientations are estimated using the particle motion of Rayleigh waves (Stachnik

126 et al. 2012).

127

128 S receiver functions

129 A seismically noisy environment in the ocean requires a visual inspection of the

130 waveforms. S waveforms from teleseismic events with $\mathrm{M}>5.5$ and epicentral distances

131 of $55-85^{\circ}$ undergo this visual inspection. Throughout this inspection, we consistently

132 used a bandpass filter of $0.03-0.1 \mathrm{~Hz}$ to exclude the primary and secondary microseism

133 bands and selected waveforms with clear onsets on the radial and vertical components.

134 Figure 2 shows examples of S waveforms selected by this inspection. Out of 1218

135 waveforms, 216 waveforms successfully passed this inspection.

136 For these selected waveforms, S-RFs are calculated by deconvolving the radial

137 component from the vertical component. We use a spectral division with a damping

138 factor for the deconvolution and apply a low-pass filter to the deconvolution results:

$$
\operatorname{SRF}(t)=\frac{1}{\sqrt{2 \pi}} \int_{-\infty}^{\infty} \frac{U_{Z}(\omega) U_{R}^{*}(\omega)}{U_{R}(\omega) U_{R}^{*}(\omega)+N_{R}(\omega) N_{R}^{*}(\omega)} \operatorname{LPF}(\omega) \exp (i \omega t) d \omega,
$$

140 where $\operatorname{SRF}(t)$ represents the time series of S-RF; $U_{Z}(\omega)$ and $U_{R}(\omega)$ represent

141 vertical and radial component records in the frequency domain, respectively; $N_{R}(\omega)$ 
142 represents a pre-signal record on the radial component (i.e., noise contribution); and the

143 asterisk signifies complex conjugate. The low-pass filter, $\operatorname{LPF}(\omega)$, is given by

$$
L P F(\omega)=\frac{1}{\sqrt{2} a} \exp \left(-\frac{\omega^{2}}{4 a^{2}}\right) .
$$

145 Here, the factor $a$ determines the cutoff frequency, which is set to 0.8 . The

146 normalization constant $(1 / \sqrt{2} a)$ compensates for energy loss due to filtering, depending

147 on the definition of the Fourier transform. Time windows for the deconvolution start

148 and end $50 \mathrm{~s}$ before and $150 \mathrm{~s}$ after the direct $\mathrm{S}$ arrival, respectively. After the

149 deconvolution, resultant S-RFs undergo time- and polarity-reversal for visualization

150 purposes.

151 For further selecting S-RFs of good quality, we examine the waveform similarity

152 between S-RFs from different teleseismic events. For each station, we calculate crosscorrelation coefficients (CCs) between all S-RF pairs and retain S-RFs that show

154 moderately high-similarity $(\mathrm{CC}>0.35)$ to more than half of all data. We find that this

155 thresholding effectively rejects S-RFs with anomalous features, such as the base-line

156 drift or high-frequency oscillation, especially for stations JPB4, JS4, and YMB3 (Figure

157 3). Unfortunately, we were not able to retain adequate numbers of data for the other

158 stations, which is due to short observation periods or high noise levels. For the three successful stations, we selected S-RFs and use the stacked waveform as the input data 
160 for the subsequent inversion analysis (Figure 3, green lines).

\section{Transdimensional inversion}

163 To constrain the parameters of seismic velocity models, we perform transdimensional

164 inversion of an S-RF waveform. This inversion method uses a reversible-jump Markov-

165 chain Monte Carlo (RJMCMC) algorithm (Green 1995) that allows the number of

166 unknowns to be unknown. The algorithm automatically determines the number of

167 unknowns in a balance between the data fit and parsimony. This feature can reduce the

168 subjectivity of the model parameter choice. For RF inversion, it can eliminate the

169 subjective choice of the layer number. Many RF studies have used the RJMCMC

170 algorithm for inverse problems in recent years (Piana Agostinetti and Malinverno 2010,

171 2018; Akuhara et al. 2020). Some of them have performed joint inversion with surface

172 wave dispersion curves (Bodin et al. 2012; Calò et al. 2016), whereas detailed inversion

173 settings differ among studies. The following sections elaborate on specific setting in this

174 study. Notably, one can reproduce the inversion setting of this paper using a computer

175 program package, SEIS_FILO (Akuhara 2021).

176 The goal of the RJMCMC algorithm is to sample the posterior probability distribution

177 of the model parameters $\left(\boldsymbol{m}_{k}\right)$ and the hyperparameter $(k)$ under a condition of a given 
178 data vector $(\boldsymbol{d})$. Here, the model parameter vector $\boldsymbol{m}_{k}$ has a variable dimension, which

179 is a function of the hyperparameter $k$. According to Bayes' theorem, the posterior

180 probability can be expressed as the product of a prior probability and a likelihood:

$$
P\left(k, \boldsymbol{m}_{k} \mid \boldsymbol{d}\right)=D \cdot P\left(k, \boldsymbol{m}_{k}\right) P\left(\boldsymbol{d} \mid k, \boldsymbol{m}_{k}\right)
$$

182 where $P\left(k, \boldsymbol{m}_{k} \mid \boldsymbol{d}\right)$ is the posterior probability, $P\left(k, \boldsymbol{m}_{k}\right)$ is the prior probability,

$183 P\left(\boldsymbol{d} \mid k, \boldsymbol{m}_{k}\right)$ is the likelihood, and $D$ is a normalization constant. For RF inversion,

184 prior probability reflects our knowledge on subsurface structures, and likelihood

185 indicates the goodness of waveform fit. Ambiguity in $D$ hampers the direct calculation

186 of the posterior probability using Equation 3. Instead, RJMCMC can simulate the

187 probability through a random walk and a birth-death scheme.

188 Model parameters

189 We parameterize subsurface structure using the following hyperparameter and model

190 parameters: the number of layers $(k)$, Vs perturbation of each layer $\left(\delta \beta_{i}, i=1 \cdots k\right)$,

191 and layer interface depths $\left(z_{i}, i=1 \cdots k-1\right)$. The velocity perturbation represents the

192 difference from a reference velocity model. This reference model has smooth,

193 increasing Vp and Vs with depth (Figure 4), which we manually made by referring to

194 established Vp models from previous seismic surveys (Sato et al. 2004, 2018;

195 Nakahigashi et al. 2013) and an empirical Vp-Vs relation (Brocher 2005). While Vs can 
196 vary via parameters $\delta \beta_{i}, \mathrm{Vp}$ is fixed at the value of the reference model. Density is

197 scaled to Vp with an empirical relation (Brocher 2005). For the seawater, the acoustic

198 velocity and density are assumed to be $1.5 \mathrm{~km} / \mathrm{s}$ and $1.0 \mathrm{~g} / \mathrm{cm}^{3}$, respectively.

\section{Prior probability}

200 Assuming independence of model parameters, the prior probability, $P\left(k, \boldsymbol{m}_{k}\right)$, may be

201 expressed as

$$
P\left(k, \boldsymbol{m}_{k}\right)=P(k) P\left(z_{1}, \cdots, z_{k} \mid k\right) P\left(\delta \beta_{1}, \cdots, \delta \beta_{k+1} \mid k\right) .
$$

203 We assume a truncated uniform prior for the number of layers $(k)$, which is expressed

204 as:

205

$$
P(k)= \begin{cases}\frac{1}{k_{\max }-k_{\min }}, & k_{\min } \leq k<k_{\max } \\ 0, & \text { else }\end{cases}
$$

$206 k_{\min }$ and $k_{\max }$ are set to 1 and 31 , respectively, throughout this study. We also use a

207 non-informative prior for interface depths, which is given by

$208 P\left(z_{1}, \cdots, z_{k} \mid k\right)=\left\{\begin{array}{ll}\frac{k !}{\left(z_{\max }-z_{\min }\right)^{k}}, & z_{\min } \leq z_{i} \leq z_{\max } \\ 0, & \text { else }\end{array} \quad\right.$ for all $\mathrm{i}=1, \cdots, \mathrm{k}$.

209 Equation 6 corresponds to the Dirichlet distribution, which assumes that the layer

210 interfaces are uniformly distributed over the range from $z_{\min }$ to $z_{\max }$ (Dosso et al.

211 2014). We set $z_{\min }$ and $z_{\max }$ to the sea depth and to $110 \mathrm{~km}$, respectively.

212 For Vs perturbations, we use Gaussian distribution with a zero mean: 


$$
P\left(\delta \beta_{1} \cdots \delta \beta_{k+1} \mid k\right)=\prod_{i=1}^{k+1} \frac{1}{\sqrt{2 \pi \sigma_{\delta \beta}^{2}}} \exp \left(-\frac{\delta \beta_{i}^{2}}{2 \sigma_{\delta \beta}^{2}}\right)
$$

214 where the standard deviation, $\sigma_{\delta \beta}$, reflects the reliability of the reference velocity

215 model. We set $\sigma_{\delta \beta}$ to $0.4 \mathrm{~km} / \mathrm{s}$.

\section{$216 \quad$ Likelihood}

217 We use a multivariate Gaussian distribution to formulate the likelihood:

$$
P\left(\mathbf{d} \mid k, \mathbf{m}_{k}\right)=\frac{1}{\sqrt{(2 \pi)^{N}|\mathbf{C}|}} \exp \left[-\frac{1}{2}\left\{\mathbf{g}\left(k, \mathbf{m}_{k}\right)-\mathbf{d}\right\}^{\mathrm{T}} \mathbf{C}^{-1}\left\{\mathbf{g}\left(k, \mathbf{m}_{k}\right)-\mathbf{d}\right\}\right] .
$$

219 Here, $\boldsymbol{C}$ is a covariance matrix and $\mathbf{g}\left(k, \mathbf{m}_{k}\right)$ is a synthetic S-RF. The covariance

220 matrix is formulated as $C_{i j}=\sigma^{2} r^{(j-i)^{2}}$, where $\sigma$ is the standard deviation of the data

221 noise and $r$ is the temporal correlation (Bodin et al. 2012). We fix $\sigma$ at the time-

222 averaged value of the RF standard error obtained through the stacking process. We

223 associate the temporal correlation with the Gaussian low-pass filter via $r=$

$224 \exp \left(-(a \Delta t / 2)^{2}\right)$, where $\Delta t$ represents the sampling interval.

225 A synthetic S-RF $\mathbf{g}\left(k, \mathbf{m}_{k}\right)$ is computed by the propagator matrix method (Thomson

226 1950). The method allows us to fully consider the reverberated phases, even with a

227 water layer. The earth-flattening transformation is employed to account for the curvature

228 of the Earth. The calculated radial and vertical component seismograms are converted into S-RFs through deconvolution, low-pass filtering, and time- and polarity-reversal.

230 For this deconvolution, we use a water-level damping with a factor of 0.001 (e.g., 
231 Clayton and Wiggins 1976). Here, the implemented deconvolution technique differs

232 from what we use for the observation data for easy implementation.

\section{Probabilistic sampling by reversible-jump Markov-chain Monte Carlo}

234 The RJMCMC iteratively explores a transdimensional model space through a random

235 walk and a birth-death scheme. At every iteration, the RJMCMC proposes a new model

$236\left(\boldsymbol{m}^{\prime}{ }_{k \prime}\right)$ by modifying the model from the previous iteration $\left(\boldsymbol{m}_{k}\right)$. This modification

237 includes adding a layer (a birth proposal; $k^{\prime}=k+1$ ), removing a layer (a death

238 proposal; $\left.k^{\prime}=k-1\right)$, moving a layer interface $\left(z_{i}^{\prime}=z_{i}+\epsilon_{z}\right)$, and perturbing Vs of a

239 layer $\left(\delta \beta_{i}^{\prime}=\delta \beta_{i}+\epsilon_{\delta \beta}\right)$. The amount of modification, $\epsilon_{Z}$ and $\epsilon_{\delta \beta}$, is extracted from

240 a Gaussian distribution with a zero-mean and a standard deviation of $0.5 \mathrm{~km}$ and 0.2

$241 \mathrm{~km} / \mathrm{s}$, respectively. Adding the $k^{\prime}$ th layer requires setting properties of the new layer

242 (i.e., $z_{k^{\prime}}$ and $\delta \beta_{k^{\prime}}$ ). These properties are randomly determined using the same

243 probability distribution as the prior probability (Dosso et al. 2014).

244 After the proposal, the RJMCMC judges a proposed model to be accepted or not using a

245 Metropolis-Hastings-Green criterion (Green 1995; see Appendix 1). If the model is

246 accepted, the accepted model is used in the next iteration to further make a new

247 proposal. Otherwise, the previous model is held and used in the next iteration for a

248 proposal. We perform 1,000,000 iterations, but the first 500,000 iterations are discarded 
to avoid dependency on the initial state (so-called burn-in period). After this burn-in

250 period, we save models at every 500th iterations to simulate the posterior probability

251 distribution. We run 100 mutually interacted Markov-chains using a parallel tempering

252 technique, which offers a more effective way of exploring a multidimensional space

253 (Sambridge 2014; see Appendix 1).

\section{Results and interpretation}

255 Each inverted velocity structure shows a velocity decrease at the mantle depth, and the depths vary among sites (Figures 4-6). We interpret these velocity decreases as the

257 LAB, a boundary between the high-velocity lithosphere and low-velocity asthenosphere. We qualitatively define the LAB depths as depths where the velocity starts decreasing, which follows $45 \mathrm{~km}$ depth beneath the Yamato Basin (station YMB3) and Japan Basin (station JPB4) and $70 \mathrm{~km}$ depth beneath the Yamato Rise (station JS4).

261 The results also provide insights into the crustal thickness. The station YMB3 and JPB4 exhibit evident velocity discontinuities at $\sim 20 \mathrm{~km}$ and $\sim 10 \mathrm{~km}$ depth, respectively. These discontinuities are most likely to represent the Moho. The thicker crust obtained

264 beneath the Yamato Basin agrees with previous seismic surveys (Hirata et al. 1989; Sato et al. 2006, 2018; Nakahigashi et al. 2013). No sharp velocity discontinuity, potentially corresponding to the Moho, is observed for station JS4. Instead, the velocity gradually 
267 increases to $30 \mathrm{~km}$ of depth. Considering a typical mantle Vs of $\sim 4.6 \mathrm{~km} / \mathrm{s}$, the Moho

268 likely exists at $20-30 \mathrm{~km}$ depth. These estimated Moho depths roughly agree with

269 seismic surveys.

270 Notably, all results indicate an extremely low Vs $(<1 \mathrm{~km} / \mathrm{s})$ immediately beneath the

271 seafloor, most likely reflecting water-saturated sediments. According to laboratory

272 measurements, such slow velocities seem natural for water-saturated marine sediments

273 (Hamilton 1979; Bowles 1997). Most seismic studies have rarely considered low-

274 velocity sediments when they focus on mantle structures. However, we found that the

275 low velocity is necessary and should not be ignored to explain overall reduced

276 amplitudes in observed waveforms. We will provide further discussion for this

277 statement in the following section. Below this layer, we obtain relatively higher

278 velocities but still lower than $1.0 \mathrm{~km} / \mathrm{s}$. Further below, there exist layers with Vs $>1$

$279 \mathrm{~km} / \mathrm{s}$, which we considered as the crust.

280 We acknowledge that the sampled models underestimate the amplitudes of the negative

281 peak seen in the observation. This underestimation can result from deconvolution. A

282 damping factor stabilizing the deconvolution suppresses S-RF amplitudes under the

283 presence of low-velocity sediments, which will be discussed in detail in the following

284 section. Other possible causes of this underestimation are lateral heterogeneity, 
285 including dipping layer interfaces and anisotropy. Unevenly distributed teleseismic

286 events, mostly from the Tonga-Kermadec subduction zone, likely prohibit such a

287 dipping layer or anisotropy effect from diminishing through stacking. Whatever the

288 cause, this amplitude underestimation could distort the estimations of the velocity

289 contrast at the LAB. The LAB depths would be less susceptive to this effect because the

290 predicted waveforms explain the peak locations well.

291

292 Discussion

\section{Contribution of sediment to S-receiver functions}

294 Though not the center of focus, our inversion analysis has predicted thin, low-velocity

295 layers at the top of the resulting models. This prediction may seem peculiar because

296 low-frequency waveforms $(<0.1 \mathrm{~Hz})$ are usually insensitive to thin layers. Another

297 peculiarity lies in the considerably small amplitudes of the observed S-RFs, which are

$298 \sim 20 \%$ of the ordinary expectation. Understanding these peculiarities seems essential to

299 appreciate our inversion results. The following paragraphs provide a unified explanation

300 for these features, where spectral notches caused by sediment reverberations play a role.

301 The sediment reverberations are inherent in ocean environments. Thus, insights

302 presented here will be suited to other offshore S-RF studies. 
303 Consider simple structure models consisting of water, sediment, and mantle layers, with

304 varying sediment Vs (Figure 8a). Synthetic S-RFs by the propagator matrix method and

305 the water-level deconvolution exhibit decreasing amplitudes with an increasing velocity

306 contrast at the sediment-mantle interface. The degree of this suppression depends on a

307 damping factor imposed on the deconvolution (Figure 8b-d). Without damping, where

308 the amplitude reduction mostly reflects a magnified S-to-S transmission coefficient at

309 the interface, we only obtain a slight peak reduction to $\sim 0.35$ even for the extreme case

310 (Figure 8b). This trivial reduction $(\sim 30 \%)$ is insufficient to explain the observed

311 amplitude reduction ( $\sim 80 \%)$. A damping factor added to a deconvolution denominator

312 exerts a more significant control over the S-RF amplitudes and allows the reproduction

313 of the observed peak amplitudes (Figure 8c, d). This tendency still holds even if we

314 employ more complex, realistic velocity models (Figure 8e-h).

315 Algebraic formulation of the reverberation phases offers further insight into the

316 damping effects. Assume a simple water-sediment-mantle model (Figure 8a) and a

317 vertical incidence of a teleseismic $\mathrm{S}$ waveform to the model. The power spectrum of the

318 radial-component response, given by Equation 18 in Appendix 2, has spectral notches,

319 and the notch depths increase with an increasing velocity contrast at the interface

320 (Figure 9a). At a higher velocity contrast, such "deep" notches are more likely subjected 
321 to damping effects. For the observation data, high-level noise can also fill in these

322 notches. Such a spectral fill in will increase the denominator of deconvolution and thus

323 reduce S-RF amplitudes. Figure $9 \mathrm{~b}$ confirms this situation through a numerical

324 calculation using the propagator matrix method, which considers an oblique incidence

325 of a waveform and includes secondary effects such as P-to-S conversions and the sea

326 water layer. The resultant spectrum still indicates similar spectral notches to algebraic

327 ones.

328 The above discussion implies a tradeoff between the sediment Vs and the damping

329 value. Our arbitral selection of the damping factor during inversion possibly biases the

330 estimated sediment Vs (and their thicknesses), but we found that this choice does not

331 affect LAB depths drastically. We acknowledge that we employed different damping

332 schemes for the observed and synthetic S-RF calculations (frequency-dependent

333 damping vs. constant water-level damping). Effects from various damping schemes

334 should be investigated in the future. Alternatively, deconvolution may be avoided using

335 transfer function-based techniques (Bodin et al. 2014; Frederiksen and Delaney 2015;

336 Akuhara et al. 2019).

337 Lateral variation in lithospheric structure

338 We have performed the inversion analysis for three good-conditioned stations, and the 
339 results show the thickest lithosphere beneath the Yamato Rise. Here, we argue that S-

340 RFs from the other stations qualitatively support this finding. Figure $\mathbf{1 0}$ shows a stack

341 of time-to-depth converted S-RFs at each station, including S-RFs rejected by the CC

342 criteria. We converted time to depth using the three median models from the inversion

343 results (Blue lines in Figures 5-7), assuming a laterally homogeneous structure across

344 each tectonic domain, i.e., we use the JPB4 model for migrating JPB4, JPB5, and JPB6

345 data; the YMB3 model for YMB3, YMB4, and JS2 data; and the JS4 model for JS4

346 data. All stacked receiver functions show a significant negative peak representing the

347 LAB (Figure 10b). The exact depths are hard to estimate from this stacking because of

348 the broadened peak. Nevertheless, the results still imply the thickest lithosphere beneath

349 the Yamato Rise and a relatively constant thickness beneath the surrounding basins.

350 An independent surface wave tomography study (Yoshizawa et al. 2010) also indicates

351 the thickened lithosphere beneath the Yamato Rise (Figure 11). Their model shows a

352 high $V_{\text {S }}$ zone at shallow mantle depths $(30-60 \mathrm{~km})$ beneath the Yamato Rise (Figure

353 11b), and its lateral extent roughly corresponds to that of the topographic high (Figure

354 11a). A strong velocity contrast resides around $60-80 \mathrm{~km}$ depth, which agrees with our

355 inverted model. The contrast becomes relatively obscure further southward, beneath the

356 Yamato Basin. However, our estimated LAB depth (45 km beneath the YMB3) seems 
consistent with their model.

358 The depth-converted S-RFs in Figure 10 also offer implications on the crustal

359 thickness. The first positive peak can represent the combination of S-to-P converted

360 phases from the sediment-crust, intra-crust, and Moho discontinuities, and thus, its peak

361 width will roughly correspond to the crustal thickness. Consequently, the results

362 indicate the thickest crustal thickness beneath the Yamato Rise, moderate thicknesses

363 beneath the Yamato Basin, and thin thicknesses beneath the Japan Basin. This first-order

364 feature is consistent with active-source seismic surveys (Hirata et al. 1989; Sato et al.

365 2004, 2018, 2020; Nakahigashi et al. 2013). Interestingly, the Yamato and Japan Basins

366 seem to have comparable LAB depths, as suggested from inversion results. This

367 similarity contrasts with the observed variation in crustal thicknesses. We further

368 discuss this point in the subsequent section.

\section{Tectonic implications}

370 This study has identified the LAB beneath the Sea of Japan back-arc basin. Results have

371 shown (1) thick lithosphere beneath the Yamato Rise and (2) a comparable lithosphere

372 thickness beneath the Yamato and Japan Basins. Whereas an ambient noise tomographic

373 study has implied a similar feature (Zheng et al. 2011), our S-RF analysis has

374 emphasized it through its high-resolution constraints. This section describes tectonic 
375 implications from the obtained first-order features of the lithosphere. Figure 12

376 schematically shows our interpretations.

377 Many studies assume that the Yamato Rise is a continental fragment isolated from the

378 Asia continent (Tamaki 1985; e.g., Kurashimo et al. 1996). The crustal Vp has

379 supported this hypothesis, which is lower than typical velocities for oceanic crusts (Sato

380 et al. 2018). Tectonic reconstruction models suggest that the Yamato Rise lies adjacent

381 to the Sikhote Alin at the pre-rift stage (Kim et al. 2007). In the vicinity, northeastern

382 China, an S-RF study has identified the LAB at $\sim 150 \mathrm{~km}$ depth (Zhang et al. 2014),

383 which may roughly indicate the original lithosphere thickness beneath the Yamato Rise.

384 Considering the current LAB depth $\sim 70 \mathrm{~km}$ obtained by this study, the lithosphere may

385 undergo lateral extension by a factor of $\sim 2$ through the rifting process. Such an

386 extension can induce normal faulting in the crust and contribute to trough formation,

387 which appears in the seafloor topography.

388 The origin of the Yamato Basin, which has an anomalously thick crust, is under debate.

389 Some studies interpreted the crust as an extended continental crust, whereas others as a

390 thickened oceanic crust. In contrast, there is no doubt that the seafloor spreading is the

391 origin of the Japan Basin, judging from the lineation pattern in the seafloor magnetic

392 anomaly (Seama and Isezaki 1990). The estimated velocity structures with comparable 
393 LAB depths may imply that the Yamato Basin also originates from the seafloor

394 spreading like the Japan Basin, assuming that the LAB depths primarily reflect the

395 thermal state and thus depend on the age (Stein and Stein 1996; Kawakatsu et al. 2009;

396 Schmerr 2012). Note that the two basins have similar ages of $19-20$ Myr (Kaneoka et

397 al. 1992). We argue that our estimated lithospheric thickness ( $45 \mathrm{~km})$ agrees with

398 observations from other ocean regions with similar lithospheric ages (Rychert et al.

3992020 and references therein). Our results do not exclude the possibility that the

400 lithospheric extension has formed the Yamato Basin. However, if this true, there would

401 be no anticipation that both basins show consistent thicknesses.

402 Whereas we have observed evident indicators of the LAB from S-to-P converted phases

403 across a wide area of the Sea of Japan (Figures 5-7 and 10), there is no observable LAB

404 reported beneath the Japanese Islands. Mantle upwelling flow, related to volcanisms

405 (Nakajima et al. 2001; Nakajima and Hasegawa 2007), can thermally or mechanically

406 complicate structures at the depth and may obscure the clear LAB manifestation. The

407 coherent Sp phase observed beneath the Sea of Japan suggests a mechanically strong

408 lithosphere, whereas the lithosphere likely becomes weak beneath the Japanese Islands

409 because of the volcanisms. Such contrast will be of importance for considering

410 seismogenesis around Japan. For instance, a seismogenic belt in the eastern margin of 
411 the Sea of Japan, running sub-parallel to the Japanese Island (Fukao and Furumoto

412 1975), may be attributed to strain accumulated near the transition between the strong

413 and weak lithosphere.

414 A limitation of this study lies in the sparse distribution of OBSs. So far, there has been

415 no passive seismic monitoring conducted at the Tsushima Basin. Such observation

416 would help gain further insights into the tectonics of the Sea of Japan. Owing to its

417 similar crustal features to the Yamato Basin, identifying the LAB depth beneath the

418 Tsushima Basin may (or may not) support our interpretation for the Yamato Basin.

419 Additionally, it could also help better understand interseismic deformation of the

420 southwestern Japan toward future megathrust earthquakes through kinematic modeling.

\section{Conclusion}

423 This study investigated the lithospheric structure beneath the Sea of Japan through

424 inversion of S-RF waveforms derived from the OBS data. Inverted structures show a

425 velocity decrease in the mantle depths, and we conclude the LAB is located at $\sim 45 \mathrm{~km}$

426 depth beneath the Japan and Yamato Basins and $\sim 65 \mathrm{~km}$ beneath the Yamato Rise. The

427 deepened $\mathrm{LAB}$ beneath the rise most likely reflects its continental origin, but the depth

428 is still shallower than that beneath northeastern China, suggesting lithospheric 
extension. The obtained comparable LAB depths for the Japan and Yamato Basins

430 indicate that both basins share a common tectonic origin: the back-arc spreading. The

431 origin of the enigmatic Yamato Basin has been controversial, and many active-source

432 seismic surveys have investigated shallow crustal structures for clues. This study offers

433 an additional constraint, for the first time, from the deeper lithospheric structure, which

434 owes to the high-resolution feature of receiver functions.

435 This study also discusses technical issues of S-RFs at the ocean bottom. As an

436 explanation of observed abnormally reduced amplitudes, we propose a theoretical

437 perspective on how sediment reverberations and additive damping (or noise) to the

438 deconvolution denominator can reduce S-RF amplitudes. However, our treatment of this

439 issue may not be sufficient, as implied by systematic overestimation of S-RF

440 amplitudes. This point should be further investigated in the future, which renders S-RF

441 methods using OBS data a more promising tool to decipher the lithosphere-

442 asthenosphere system.

444 Appendix 1. Acceptance criteria and parallel tempering

445 The RJMCMC algorithm aims to extract samples from model spaces such that samples

446 follow their posterior probability. Each proposed model needs to be accepted or rejected 
under the equilibrium condition. For a fixed dimension (i.e., $k=$ constant), this

Metropolis-Hastings criterion:

$$
\alpha_{M H}\left(k, \boldsymbol{m}_{k}^{\prime} \mid k, \boldsymbol{m}_{k}\right)=\min \left[1, \frac{P\left(k, \boldsymbol{m}^{\prime}\right)}{P(k, \boldsymbol{m})} \cdot \frac{P\left(\boldsymbol{d} \mid k, \boldsymbol{m}_{k}^{\prime}\right)}{P\left(\boldsymbol{d} \mid k, \boldsymbol{m}_{k}\right)} \cdot \frac{Q\left(\boldsymbol{m}_{k} \mid \boldsymbol{m}_{k}^{\prime}\right)}{Q\left(\boldsymbol{m}_{k}^{\prime} \mid \boldsymbol{m}_{k}\right)}\right] .
$$

Here, $\boldsymbol{m}_{k}$ and $\boldsymbol{m}_{k}^{\prime}$ are the last-accepted and proposed models, respectively; and

$$
\left.Q\left(\boldsymbol{m}_{k}^{\prime} \mid \boldsymbol{m}_{k}\right)=Q\left(\boldsymbol{m}_{k} \mid \boldsymbol{m}_{k}^{\prime}\right)\right)
$$

$$
\alpha_{M H}\left(k, \boldsymbol{m}_{k}^{\prime} \mid k, \boldsymbol{m}_{k}\right)=\min \left[1, \frac{P\left(k, \boldsymbol{m}^{\prime}\right)}{P(k, \boldsymbol{m})} \cdot \frac{P\left(\boldsymbol{d} \mid k, \boldsymbol{m}_{k}^{\prime}\right)}{P\left(\boldsymbol{d} \mid k, \boldsymbol{m}_{k}\right)}\right] .
$$

Equations 9 and 10 assume that the model space dimension does not change through

a random walk. Green (1995) has introduced the Metropolis-Hastings-Green criterion

that can account for the dimensional change:

$$
\alpha_{M H G}\left(k^{\prime}, \boldsymbol{m}_{k^{\prime}}^{\prime} \mid k, \boldsymbol{m}_{\boldsymbol{k}}\right)=\min \left[1, \frac{P\left(k^{\prime}, \boldsymbol{m}_{k \prime}^{\prime}\right)}{P\left(k, \boldsymbol{m}_{k}\right)} \cdot \frac{P\left(\boldsymbol{d} \mid k^{\prime}, \boldsymbol{m}_{k \prime}^{\prime}\right)}{P\left(\boldsymbol{d} \mid k, \boldsymbol{m}_{k}\right)} \cdot \frac{Q\left(k, \boldsymbol{m}_{k} \mid k^{\prime}, \boldsymbol{m}_{k^{\prime}}^{\prime}\right)}{Q\left(k^{\prime}, \boldsymbol{m}_{k^{\prime}}^{\prime} \mid k, \boldsymbol{m}_{k}\right)} \cdot|\boldsymbol{J}|\right] \text {. }
$$

460 The Jacobian $|\boldsymbol{J}|$ in Equation 11 adjusts unit volume change in the model space.

461 Specific configurations of a random walk are known to cancel out similar terms in

462 Equation 11 (Dosso et al. 2014; Sen and Biswas 2017), leading to

$$
\alpha_{M H G}\left(k^{\prime}, \boldsymbol{m}_{k^{\prime}}^{\prime} \mid k, \boldsymbol{m}_{\boldsymbol{k}}\right)=\min \left[1, \frac{P\left(\boldsymbol{d} \mid k^{\prime}, \boldsymbol{m}_{k^{\prime}}^{\prime}\right)}{P\left(\boldsymbol{d} \mid k, \boldsymbol{m}_{k}\right)}\right]
$$

464 To enhance the efficiency of model sampling, the parallel tempering technique (Geyer 


$$
\alpha_{M H}\left(k, \boldsymbol{m}_{k}^{\prime} \mid k, \boldsymbol{m}_{k}\right)=\min \left[1, \frac{P\left(k, \boldsymbol{m}^{\prime}\right)}{P(k, \boldsymbol{m})} \cdot\left\{\frac{P\left(\boldsymbol{d} \mid k, \boldsymbol{m}_{k}^{\prime}\right)}{P\left(\boldsymbol{d} \mid k, \boldsymbol{m}_{k}\right)}\right\}^{\frac{1}{T_{i}}}\right]
$$

and

$$
\alpha_{M H G}\left(k^{\prime}, \boldsymbol{m}_{k^{\prime}}^{\prime} \mid k, \boldsymbol{m}_{\boldsymbol{k}}\right)=\min \left[1,\left\{\frac{P\left(\boldsymbol{d} \mid k^{\prime}, \boldsymbol{m}_{k^{\prime}}^{\prime}\right)}{P\left(\boldsymbol{d} \mid k, \boldsymbol{m}_{k}\right)}\right\}^{\frac{1}{T_{i}}}\right] .
$$

470 Higher temperatures than unity lose the acceptance criterion to accept more models.

471 Such tempered chains can walk through the broader region in the model space consequently. However, this modification by $T_{i}$ breaks the equilibrium condition, and thus the sampled model does not simulate the posterior probability distribution. The parallel tempering technique remedies this issue by running $100 \mathrm{MCMC}$ chains with different temperature $\left(T_{i} ; i=1 \cdots 100\right)$ in parallel. At each iteration, two chains are arbitrarily selected, and their temperatures are swapped with a probability of

$$
\alpha_{P T}(i, j)=\min \left[1,\left\{\frac{P\left(\boldsymbol{d} \mid k^{j}, \boldsymbol{m}_{k^{j}}^{j}\right)}{P\left(\boldsymbol{d} \mid k^{i}, \boldsymbol{m}_{k^{i}}^{i}\right)}\right\}^{\frac{1}{T_{i}}}\left\{\frac{P\left(\boldsymbol{d} \mid k^{i}, \boldsymbol{m}_{k^{i}}^{i}\right)}{P\left(\boldsymbol{d} \mid k^{j}, \boldsymbol{m}_{k^{j}}^{j}\right)}\right\}^{\frac{1}{T_{j}}}\right]
$$
probability can be retrieved by gathering models accepted with non-tempered chains. 
481 Our inversion involves 20 chains having a unit temperature (i.e., non-tempered). For

482 the other 80 chains, we randomly set temperatures, which range from 1 to 20.

483

484 Appendix 2. Algebraic expression for sediment reverberations

485 When a plane, impulsive, unit-amplitude, upgoing, nearly-vertical SV waveform

486 incidents to this structure model, a radial-component elastic response at the sediment

487 top is approximately given by

488

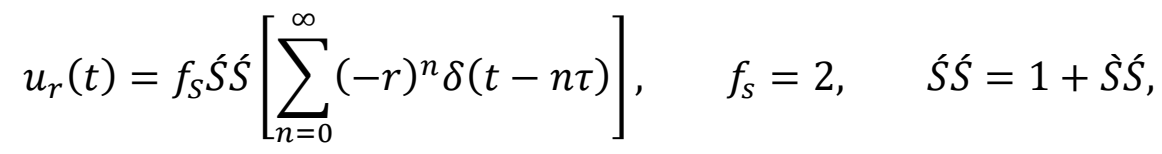

$$
\begin{aligned}
& \tau=\frac{2 h_{1}}{\beta_{1}}, \quad \grave{S} S=\frac{\rho_{2} \beta_{2}-\rho_{1} \beta_{1}}{\rho_{1} \beta_{1}+\rho_{2} \beta_{2}}
\end{aligned}
$$

489

in the time domain and

$$
U_{R}(\omega)=2(1+\grave{S} S) \frac{1}{\left(1+\grave{S} S e^{-i \omega \tau}\right)}
$$

491

in the frequency domain (Yu et al. 2015), where $h_{1}, \beta_{1}$, and $\rho_{1}$ represent a thickness,

492 Vs, and a density of the overriding sediment layer, respectively; $\beta_{2}$ and $\rho_{2}$ represent

493 Vs and a density of the half space; $f_{s}$ represents free-surface reflection; $\tau$ represents a

494 two-way travel time of S-wave passing through the sediment layer; and $\grave{S} S$ and $S ́ S$

495 represent reflection and transmission coefficients at the layer interface, respectively.

496 From equation 17, we obtain the denominator of deconvolution without damping:

$$
U_{R}(\omega) U_{R}^{*}(\omega)=\frac{2(1+\grave{S} \hat{S})^{2}}{1+\grave{S} \hat{S} \cos (\tau \omega)} .
$$


499 The teleseismic waveforms analyzed during this study are available from the

500 corresponding author on reasonable request.

\section{Competing interests}

502 The authors declare no competing interests.

\section{$503 \quad$ Funding}

504 This study was conducted as a part of Integrated Research Project on Seismic and

505 Tsunami Hazards around the Sea of Japan by the Ministry of Education, Culture, Sports,

506 Science, and Technology (MEXT) of Japan.

\section{Authors' contributions}

508 TA analyzed waveform data. TA, KN, and MS interpreted the data and designed the

509 seismic observation. All authors contribute to the data acquisition and read and

510 approved the final manuscript.

\section{Acknowledgments}

512 We thank Kazunori Yoshizawa for providing the tomography model of the Sea of Japan.

\section{References}


518 tools for flat and isotropic layered structure in the ocean Receiver Functions: Green's Function Estimation by Transdimensional Inversion and Its Application to OBS Data. J Geophys Res Solid Earth 124:1944-1961. doi: 10.1029/2018JB016499 Sediment in the Nankai Trough Forearc Inferred From Transdimensional Inversion of High-Frequency Teleseismic Waveforms. Geophys Res Lett 47:. doi: 10.1029/2020GL088280 Bodin T, Sambridge M, Tkalćić H, et al (2012) Transdimensional inversion of receiver functions and surface wave dispersion. J Geophys Res Solid Earth 117:1-24. doi: 10.1029/2011JB008560 Bodin T, Yuan H, Romanowicz B (2014) Inversion of receiver functions without deconvolution — application to the Indian craton. Geophys J Int 196:10251033. doi: 10.1093/gji/ggt431 

density in the Earth's crust. Bull Seismol Soc Am 95:2081-2092. doi: $10.1785 / 0120050077$ mantle across North America from joint inversion of long and short period seismic data. Earth Planet Sci Lett 449:164-175. doi: 10.1016/j.epsl.2016.05.054 Clayton RW, Wiggins RA (1976) Source shape estimation and devoncolution of teleseismic body waves. Geophys J R Astron Soc 151-177 dimensional Bayesian inversion for geoacoustic profile estimation. Inverse Probl 30:114018. doi: 10.1088/0266-5611/30/11/114018 Evans JR, Suyehiro K, Sacks IS (1978) Mantle structure beneath the Japan Sea-A re-examination. Geophys Res Lett 5:487-490. doi: 10.1029/GL005i006p00487 Frederiksen AW, Delaney C (2015) Deriving crustal properties from the P Coda without deconvolution: The southwestern Superior Province, North America. 

eastern margin of the Japan sea. Tectonophysics 26:247-266. doi: 10.1016/00401951(75)90093-1

Geyer CJ, Thompson EA (1995) Annealing Markov Chain Monte Carlo with Appplications to Ancestral Inference. J Am Stat Assoc 90:909-920. doi: $10.1080 / 01621459.1995 .10476590$ and Bayesian model determination. Biometrika 82:711-732. doi: 10.1093/biomet/82.4.711 Hamilton EL (1979) $V_{p} / V_{s}$ and Poisson's ratios in marine sediments and rocks. J Acoust Soc Am 66:1093-1101. doi: 10.1121/1.383344 the crust of the yamato basin, southeastern sea of japan: the final stage of back-arc spreading. Tectonophysics 165:303-314. doi: 10.1016/0040-1951(89)90055-3 589. doi: 10.1038/s41561-020-0609-y 
Formation of the Japan Sea. In: Proceedings of the Ocean Drilling Program,

Kawakatsu H, Kumar P, Takei Y, et al (2009) Seismic Evidence for Sharp 502. doi: 10.1126/science.1169499

116:1-17. doi: 10.1029/2011JB008506 

stretched continental crust in the Japan Sea. Geophys Res Lett 23:3067-3070. doi: 10.1029/96GL02765 the extended continental crust in the Yamato Basin, Japan Sea, from ocean bottom

604 seismometer survey. J Asian Earth Sci 67-68:199-206. doi:

605 10.1016/j.jseaes.2013.02.028 
607 upwelling beneath southwestern Japan and its implications for arc magmatism.

608 Earth Planet Sci Lett 254:90-105. doi: 10.1016/j.epsl.2006.11.024

610 Toru Matsuzawa, and Akira Hasegawa. J Geophys Res 106:21843-21857

611 Otofuji Y-I, Matsuda T, Nohda S (1985) Opening mode of the Japan Sea

612 inferred from the palaeomagnetism of the Japan Arc. Nature 317:603-604. doi:

$613 \quad 10.1038 / 317603 \mathrm{a} 0$

Piana Agostinetti N, Malinverno A (2010) Receiver function inversion by trans-dimensional Monte Carlo sampling. Geophys J Int 181:858-872. doi:

616 10.1111/j.1365-246X.2010.04530.x

617 Piana Agostinetti N, Malinverno A (2018) Assessing uncertainties in highresolution, multifrequency receiver-function inversion: A comparison with

619 borehole data. Geophysics 83:KS11-KS22. doi: 10.1190/geo2017-0350.1 Rychert CA, Fischer KM, Rondenay S (2005) A sharp lithosphereasthenosphere boundary imaged beneath eastern North America. Nature 436:542545. doi: $10.1038 /$ nature 03904 
624 Lithosphere-Asthenosphere Boundary. J Geophys Res Solid Earth 125:1-39. doi:

625 10.1029/2018JB016463

Rychert CA, Harmon N, Tharimena S (2018) Scattered wave imaging of the oceanic plate in cascadia. Sci Adv 4:1-8. doi: 10.1126/sciadv.aao1908 Sato H (1994) stress field and basin development in northeast Japan stress. sampling and multimodal optimization. Geophys J Int 196:357-374. doi:

$$
10.1093 / \text { gji/ggt342 }
$$

$$
\text { asthenosphere boundary near the equatorial Mid-Atlantic Ridge. Earth Planet Sci }
$$

$$
\text { Lett 566:116949. doi: 10.1016/j.epsl.2021.116949 }
$$

$$
\text { Sambridge M (2014) A Parallel Tempering algorithm for probabilistic }
$$

$$
\text { Sato H (1994) stress field and basin development in northeast Japan stress. }
$$
Geophys Res 99:

Sato T, No T, Arai R, et al (2020) Transition from continental rift to backarc basin in the southern Japan Sea deduced from seismic velocity structures. Geophys J Int 221:722-739. doi: 10.1093/gji/ggaa006 Sato T, No T, Miura S, Kodaira S (2018) Crustal characteristic variation in the central Yamato Basin, Japan Sea back-arc basin, deduced from seismic survey results. Tectonophysics 726:1-13. doi: 10.1016/j.tecto.2018.01.022 
644 seismometers and airguns. Earth, Planets Sp 56:501-510. doi:

645 10.1186/BF03352509

Sato T, Takahashi N, Miura S, et al (2006) Last stage of the Japan Sea backarc opening deduced from the seismic velocity structure using wide-angle data. Asthenosphere Boundary. Science (80- ) 335:1480-1483. doi: $10.1126 /$ science. 1215433 reversible jump Hamiltonian Monte Carlo algorithm. Geophysics 82:R119-R134. doi: 10.1190/geo2016-0010.1 
Seismol Res Lett 83:704-713. doi: 10.1785/0220110128

661

Stein S, Stein CA (1996) Thermo-Mechanical Evolution of Oceanic

662 Lithosphere: Implications for the Subduction Process and Deep Earthquakes.

663 Subduction Top to Bottom Geophys Monogr 96:1-17. doi: 10.1029/GM096p0001

664

665

10.1130/0091-7613(1985)13<475:TMOBS>2.0.CO;2

666

Tamaki K, Pisciotto K, Allan J (1990) Site 797. In: Proc. ODP, Init. Repts.

667

College Station, TX (Ocean Drilling Program), pp 323-421

668

Tatsumi Y, Otofuji Y, MAtsuda T, Nohda S (1989) Opening of the Sea of

669

JApan back-arc basin by asthenopheric injection. Tectonophysics 166:317-329.

670 doi: 10.1016/0040-1951(89)90283-7

671 Thomson WT (1950) Transmission of elastic waves through a stratified

672 medium. J Appl Phys 21:89-93; 89

673 Van Horne A, Sato H, Ishiyama T (2017) Evolution of the Sea of Japan

674 back-arc and some unsolved issues. Tectonophysics 710-711:6-20. doi:

$675 \quad 10.1016 /$ j.tecto.2016.08.020

676 Yoshizawa K, Miyake K, Yomogida K, et al (2010) 3D upper mantle structure beneath Japan and its surrounding region from inter-station dispersion 
measurements of surface waves. Phys Earth Planet Inter 183:4-19. doi: seismic stations overlying a low-velocity sedimentary layer using receiver functions. J Geophys Res B Solid Earth 120:3208-3218. doi: 10.1002/2014JB011610 and data example. Geophys J Int 165:555-564. doi: 10.1111/j.1365246X.2006.02885.x Northeast China from S-wave receiver functions. Earth Planet Sci Lett 401:196205. doi: 10.1016/j.eps1.2014.06.017 the North China Craton, northeastern China, and the Sea of Japan from ambient 
696

697 Figure 1. Tectonic setting of the study area and station arrangement. Red squares denote

698 observation sites where broadband seismometers were deployed.

699

700 Figure 2. Examples of teleseismic $\mathrm{S}$ waveforms recorded by a broadband ocean-bottom

701 seismometer. The waveforms are bandpass-filtered between $0.03-0.1 \mathrm{~Hz}$. Zero on the

702 time axis corresponds to the theoretical S arrivals.

703

704 Figure 3. S-receiver functions for each site. Black, red, and green traces represent

705 rejected, accepted, and stacked receiver functions, respectively.

706

707 Figure 4 Reference velocity models. Red, blue, and green lines represent the reference

708 models for YMB3, JS4, and JPB4, respectively. Solid lines represent the S-wave

709 velocity. Dashed lines represent the P-wave velocity. (a) Overall view. (b) Enlarged

710 view for the shallow portion.

711

712 Figure 5. Inversion results for station YMB3 located at the Yamato Basin. (a) Posterior 
713 probability of the number of layers. (b) Frequency distribution of predicted S-receiver

714 functions. The background color shows the distribution, and the green line denotes the

715 observed S-receiver function. (c, d) Posterior marginal probability of the S-wave

716 velocity at each depth bin: (c) enlarged view for the seafloor sediment; (d) overall view.

717 The background color shows the probability. Blue solid and black dashed lines denote

718 the median and reference models, respectively.

720 Figure 6. The same as Figure 5 but for station JS4 located at the Yamato Rise.

Figure 7. The same as Figure 5 but for station JPB4 located at the Japan Basin.

724 Figure 8. Forward model experiments with $(\mathrm{a}-\mathrm{d})$ simple and $(\mathrm{e}-\mathrm{h})$ more realistic

725 velocity models. (a, e) S-wave velocity (Vs) models tested through forward modeling.

726 The models have an additional water layer with a 3-km thickness, although not shown

727 in these panels. (b-d, $\mathrm{f}-\mathrm{h})$ Synthetic S-receiver functions calculated through different

728 damping: (b, f) without damping, (c, g) with a damping factor of 0.001 , and $(\mathrm{d}, \mathrm{h})$ with a

729 damping factor of 0.01. Line colors correspond to those in (a) and (e). 
731 Figure 9. Radial-component responses of a sediment layer overriding a half space. (a)

732 Algebraic expression given by Equation 18. Color notation is the same as Figure 8a.

733 (b) Numerical results.

734

735 Figure 10. Time-to-depth converted and stacked S-receiver functions (S-RFs) for each

736 station. (a) Stations locations (red squares). (b) The depth-converted, stacked S-RFs.

737 Positive and negative amplitudes are shaded in red and blue, respectively. The gray

738 shade represents the $95 \%$ confidence interval from bootstrap resampling 1000 times.

739

740 Figure 11. Comparison to surface wave tomography model. (a) Seafloor topography

741 profile. (b) Cross section of S-wave velocity model estimated by surface wave

742 tomography (Yoshizawa et al. 2010). The shallow portion $(<30 \mathrm{~km} \mathrm{depth})$ is masked by

743 the gray shade because of insufficient resolution with long-period surface waves. Blue

744 horizons roughly indicate the lithosphere-asthenosphere boundary inferred from the

745 inversion. Red squares denote station locations. (c) Profile location (red line) and station

746 locations (red squares).

747

748 Figure 12. Schematic illustration of the lithosphere-asthenosphere system across 
749 northeastern Japan, the Sea of Japan, and northeastern China.

\section{$751 \quad$ Tables}

752 Table 1. Summary of observation

\begin{tabular}{|l|l|l|}
\hline Site name & Tectonic domain & Data availability \\
\hline JPB4 & Japan Basin & $2017 / 07 / 18-2019 / 07 / 27$ \\
\hline JPB5 & Japan Basin & $2018 / 07 / 25-2018 / 10 / 17$ \\
\hline JPB6 & Japan Basin & $2017 / 07 / 18-2019 / 07 / 27$ \\
\hline YMB3 & Yamato Basin & $2013 / 10 / 18-2015 / 8 / 11$ \\
\hline YMB4 & Yamato Basin & $2013 / 10 / 18-2014 / 08 / 03,2015 / 08 / 11-2016 / 08 / 08$ \\
\hline JS2 & Yamato Basin & $2003 / 08 / 14-2003 / 11 / 15$ \\
\hline JS4 & Yamato Rise & $2002 / 12 / 01-2003 / 11 / 15$ \\
\hline
\end{tabular}

754 Table 2 Velocity models used in forward modeling.

\begin{tabular}{|l|l|l|l|l|}
\hline & Vp $(\mathrm{km} / \mathrm{s})$ & Vs $(\mathrm{km} / \mathrm{s})$ & Density & Thickness \\
\hline Seawater & 1.5 & - & $\left(\mathrm{g} / \mathrm{cm}^{3}\right)$ & $(\mathrm{km})$ \\
\hline Sediment \#1 & 1.5 & $0.07-0.7$ & 1.0 & 3 \\
\hline
\end{tabular}




\begin{tabular}{|l|l|l|l|l|}
\hline Sediment \#2 & 2.1 & 0.7 & 1.9 & 0.1 \\
\hline Crust \#1 & 4.3 & 2.5 & 2.4 & 3 \\
\hline Crust \#2 & 6.0 & 3.5 & 2.7 & 4 \\
\hline Mantle & 8.1 & 4.6 & 3.3 & - \\
\hline
\end{tabular}


Figures

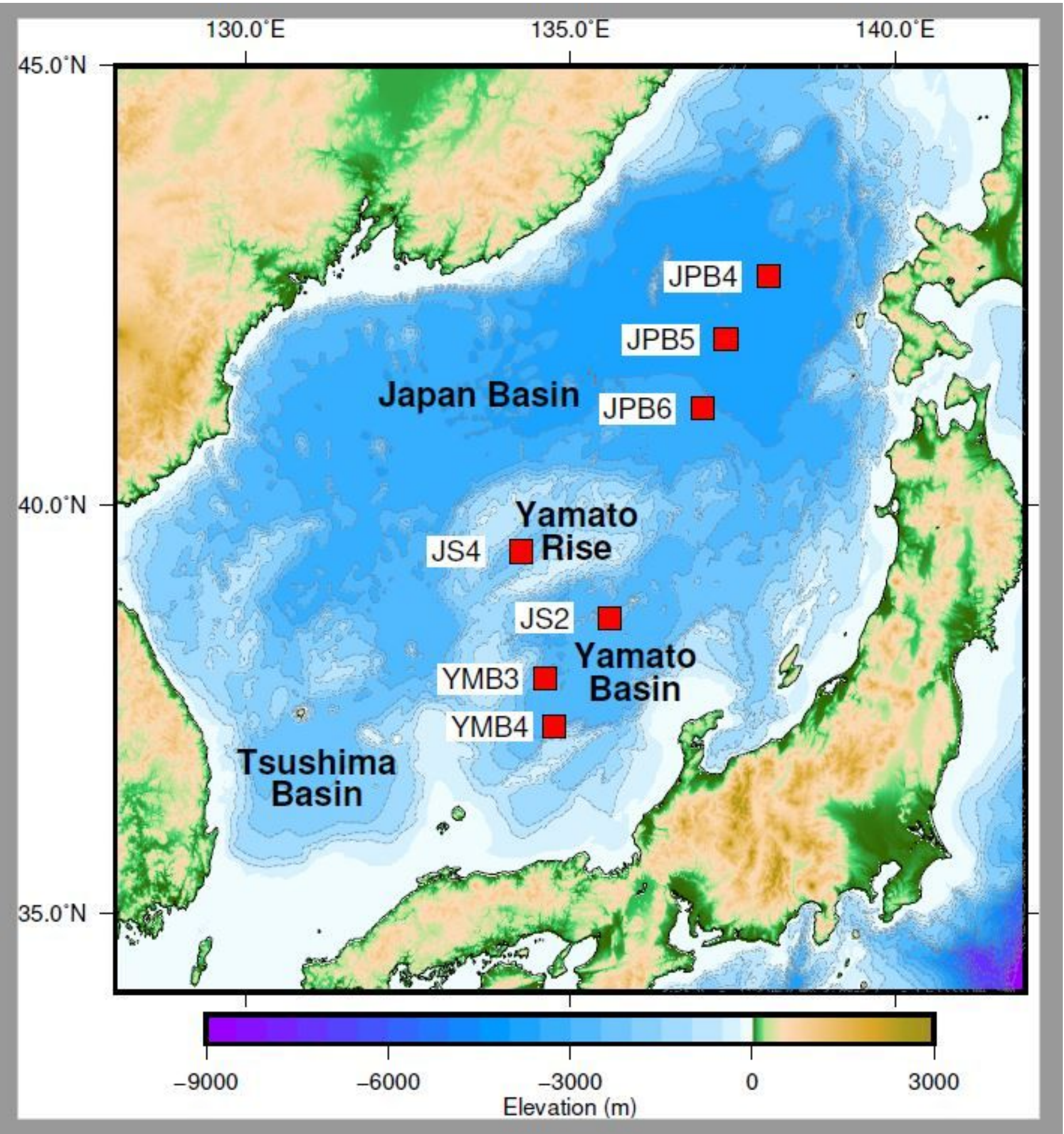

Figure 1

Tectonic setting of the study area and station arrangement. Red squares denote observation sites where broadband seismometers were deployed. Note: The designations employed and the presentation of the material on this map do not imply the expression of any opinion whatsoever on the part of Research 
Square concerning the legal status of any country, territory, city or area or of its authorities, or concerning the delimitation of its frontiers or boundaries. This map has been provided by the authors.



Figure 2

Examples of teleseismic S waveforms recorded by a broadband ocean-bottom seismometer. The waveforms are bandpass-filtered between $0.03-0.1 \mathrm{~Hz}$. Zero on the time axis corresponds to the theoretical $\mathrm{S}$ arrivals. 



Figure 3

S-receiver functions for each site. Black, red, and green traces represent rejected, accepted, and stacked receiver functions, respectively. 


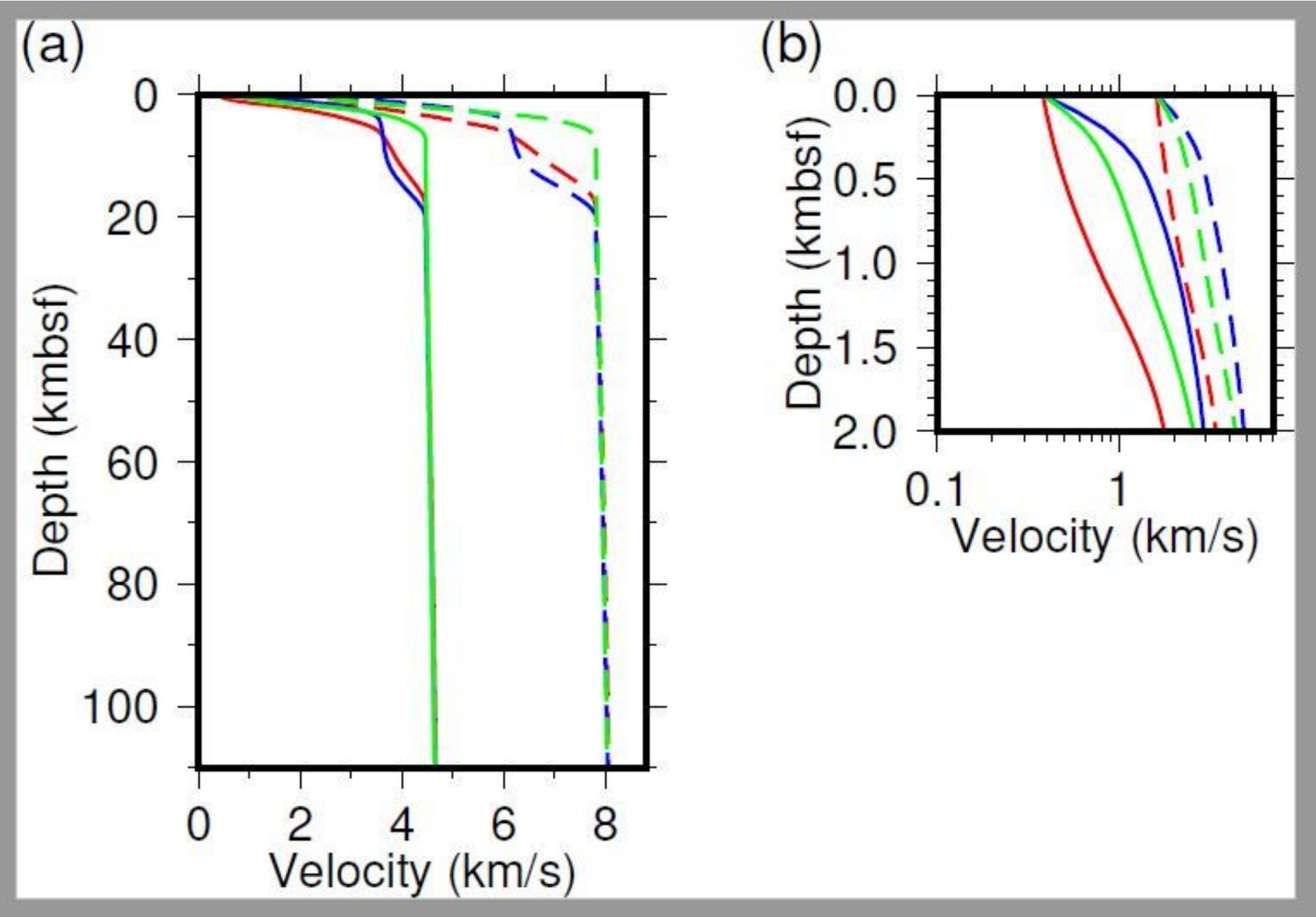

Figure 4

Reference velocity models. Red, blue, and green lines represent the reference models for YMB3, JS4, and JPB4, respectively. Solid lines represent the S-wave velocity. Dashed lines represent the P-wave velocity. (a) Overall view. (b) Enlarged view for the shallow portion. 
(a)

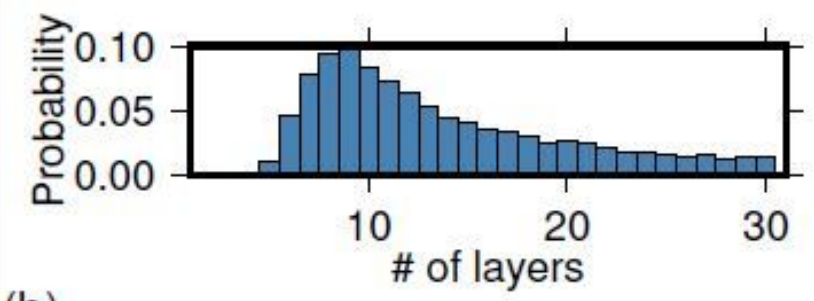

(b)

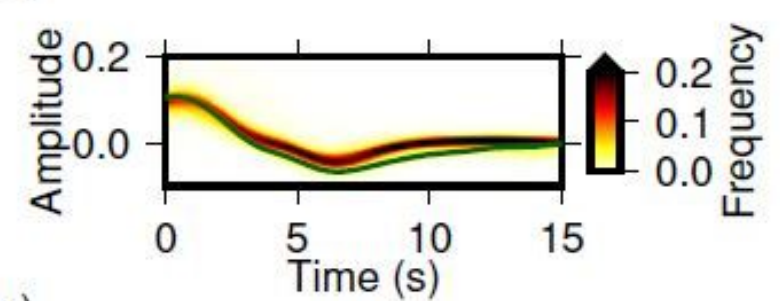

(c)

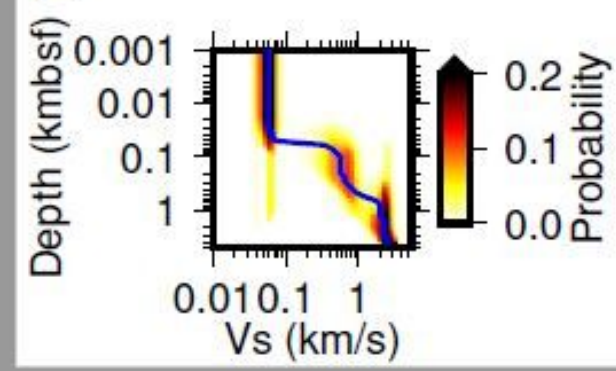

(d)

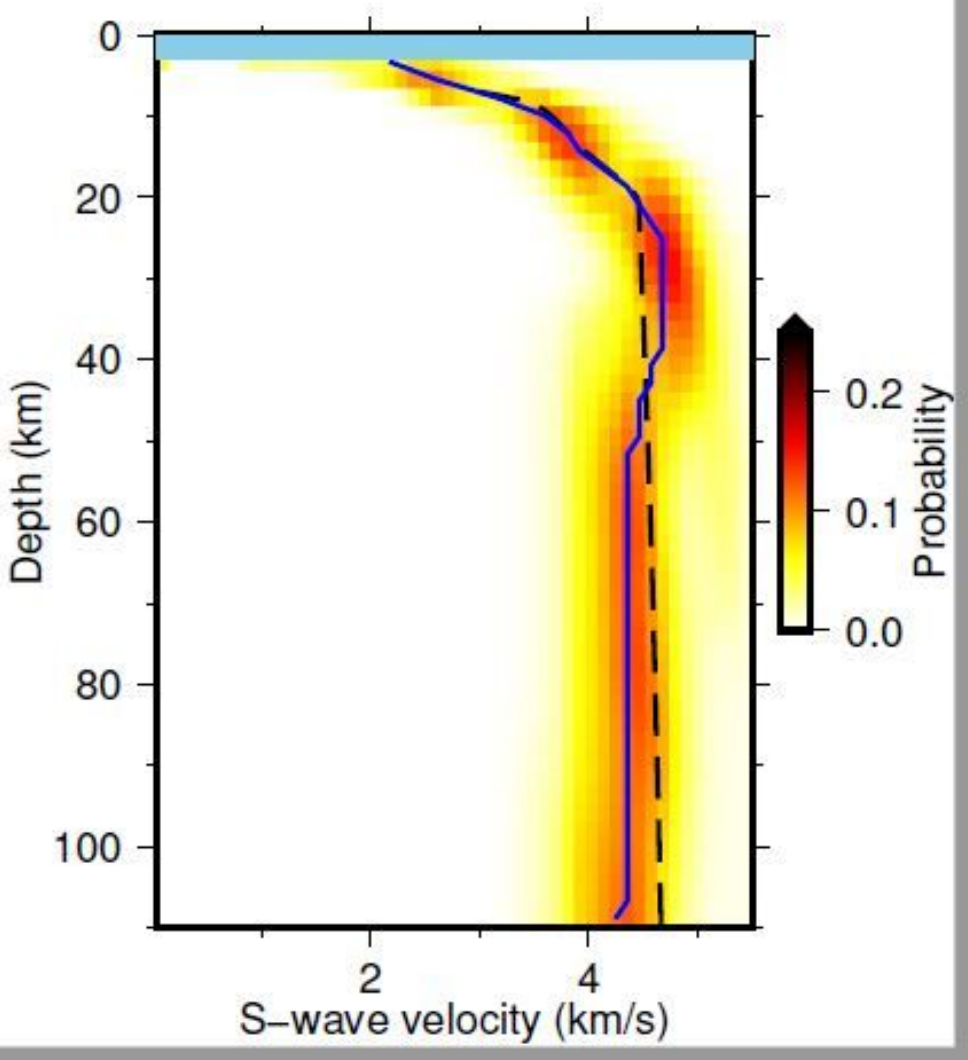

Figure 5

Inversion results for station YMB3 located at the Yamato Basin. (a) Posterior probability of the number of layers. (b) Frequency distribution of predicted S-receiver functions. The background color shows the distribution, and the green line denotes the observed S-receiver function. (c, d) Posterior marginal probability of the S-wave velocity at each depth bin: (c) enlarged view for the seafloor sediment; (d) overall view. The background color shows the probability. Blue solid and black dashed lines denote the median and reference models, respectively. 
(a)



(b)

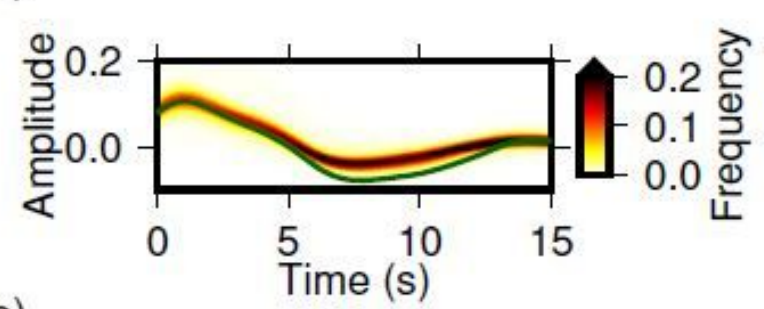

(c)

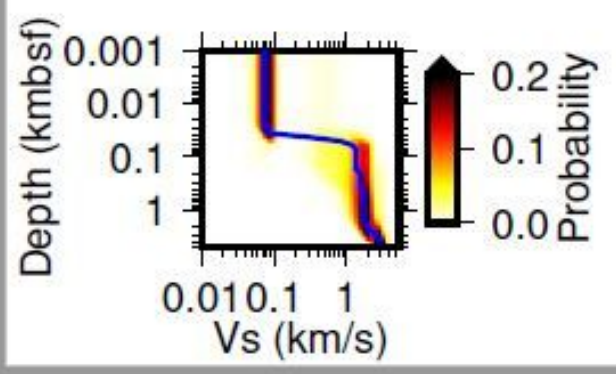

(d)

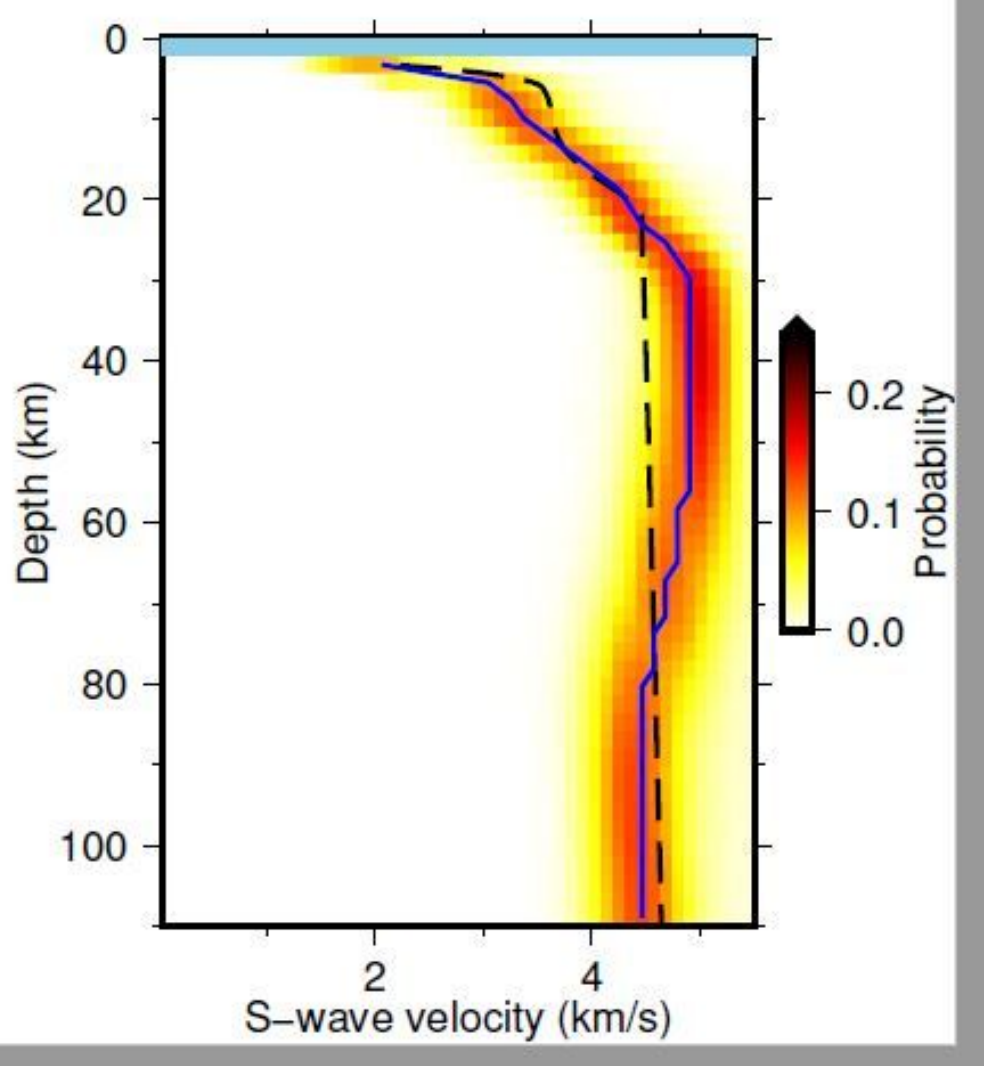

Figure 6

The same as Figure 5 but for station JS4 located at the Yamato Rise. 
(a)

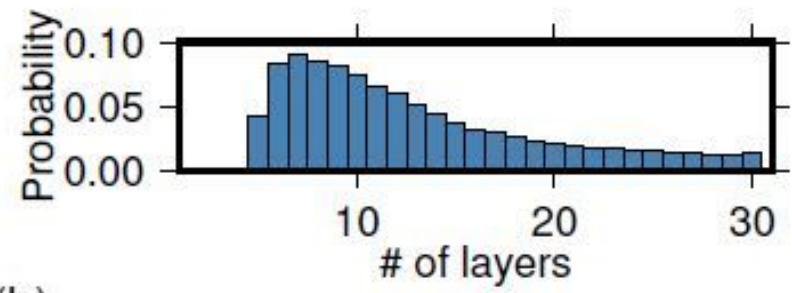

(b)

(c)
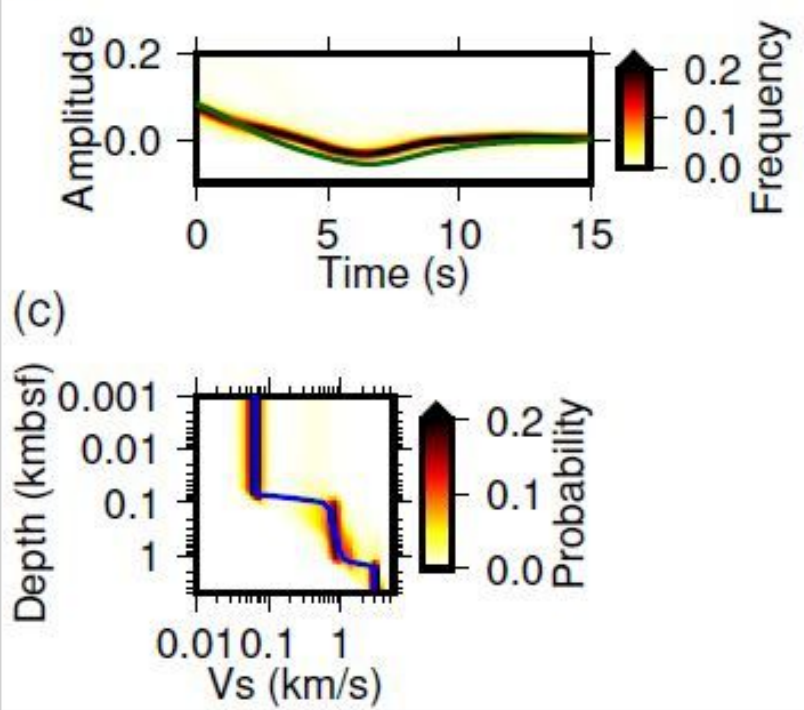

(d)



Figure 7

The same as Figure 5 but for station JPB4 located at the Japan Basin.

(a)

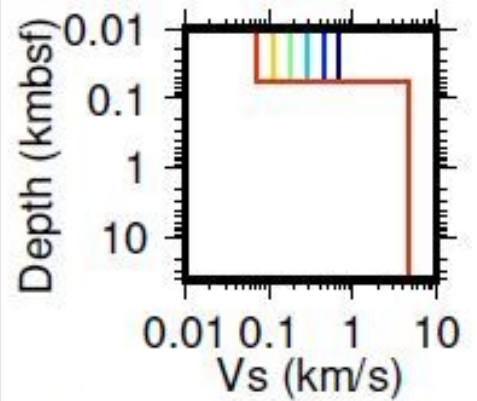

(e)

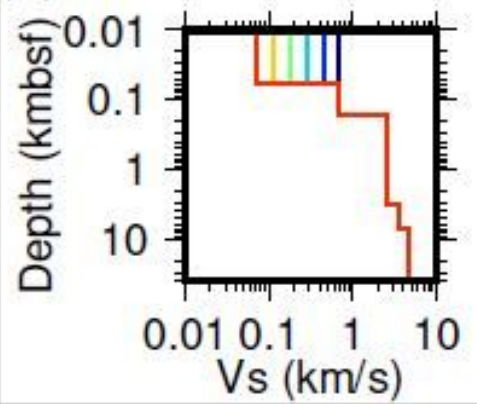

(b)

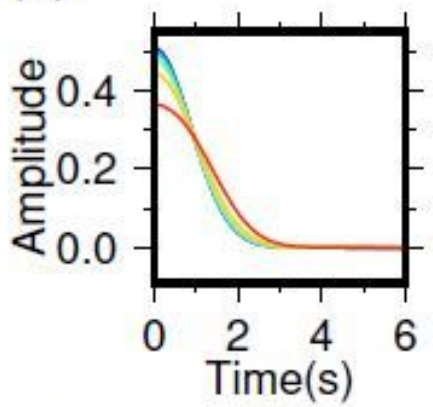

(f)

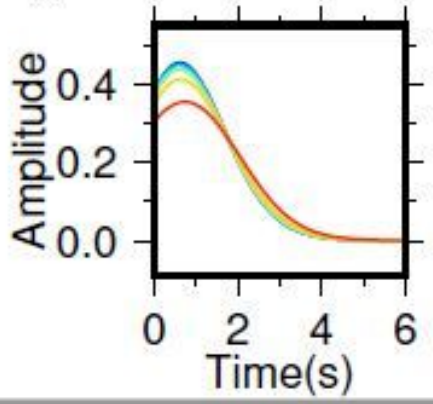

(c)

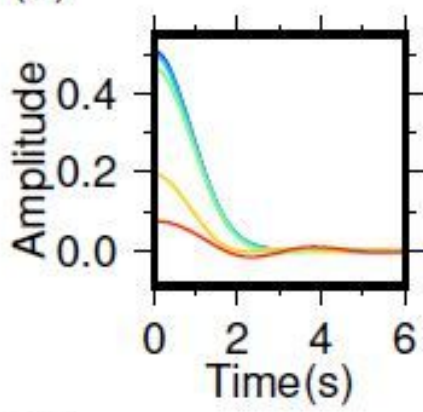

(g)

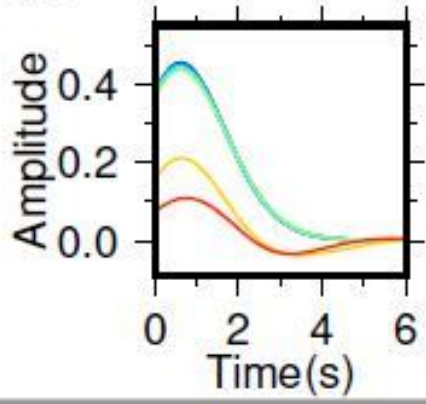

(d)

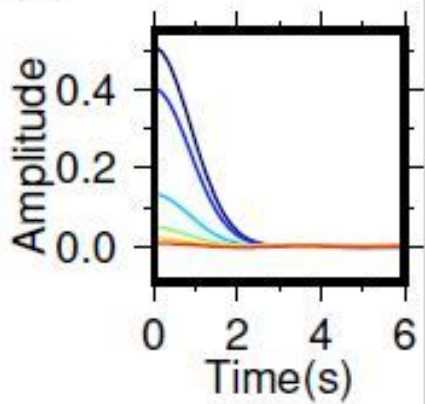

(h)




Figure 8

Forward model experiments with $(a-d)$ simple and $(e-h)$ more realistic velocity models. $(a, e)$ S-wave velocity (Vs) models tested through forward modeling. The models have an additional water layer with a 3-km thickness, although not shown in these panels. $(b-d, f-h)$ Synthetic S-receiver functions calculated through different damping: $(b, f)$ without damping, $(c, g)$ with a damping factor of 0.001 , and $(d, h)$ with a damping factor of 0.01 . Line colors correspond to those in (a) and (e).

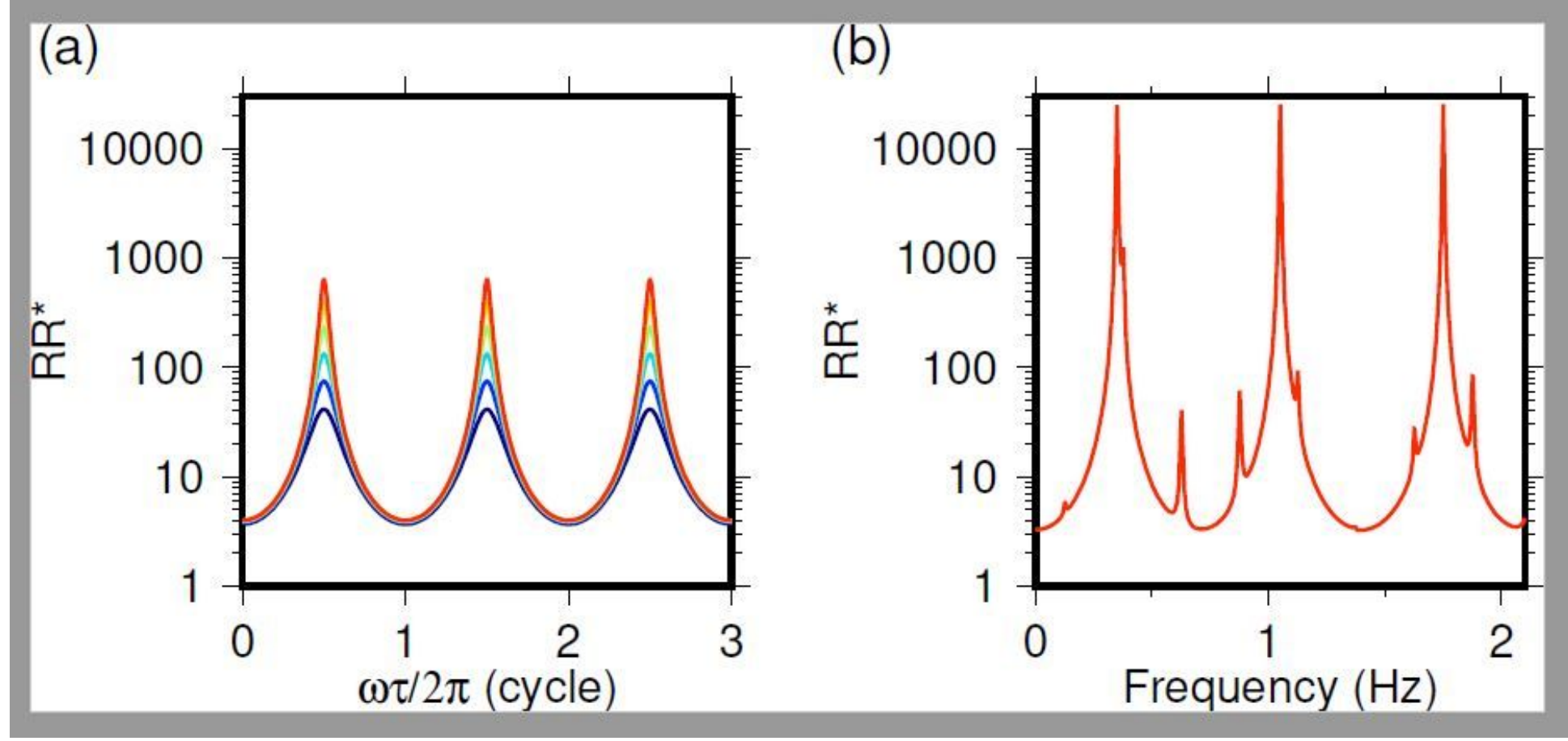

\section{Figure 9}

Radial-component responses of a sediment layer overriding a half space. (a) Algebraic expression given by Equation 18. Color notation is the same as Figure 8a. (b) Numerical results. 


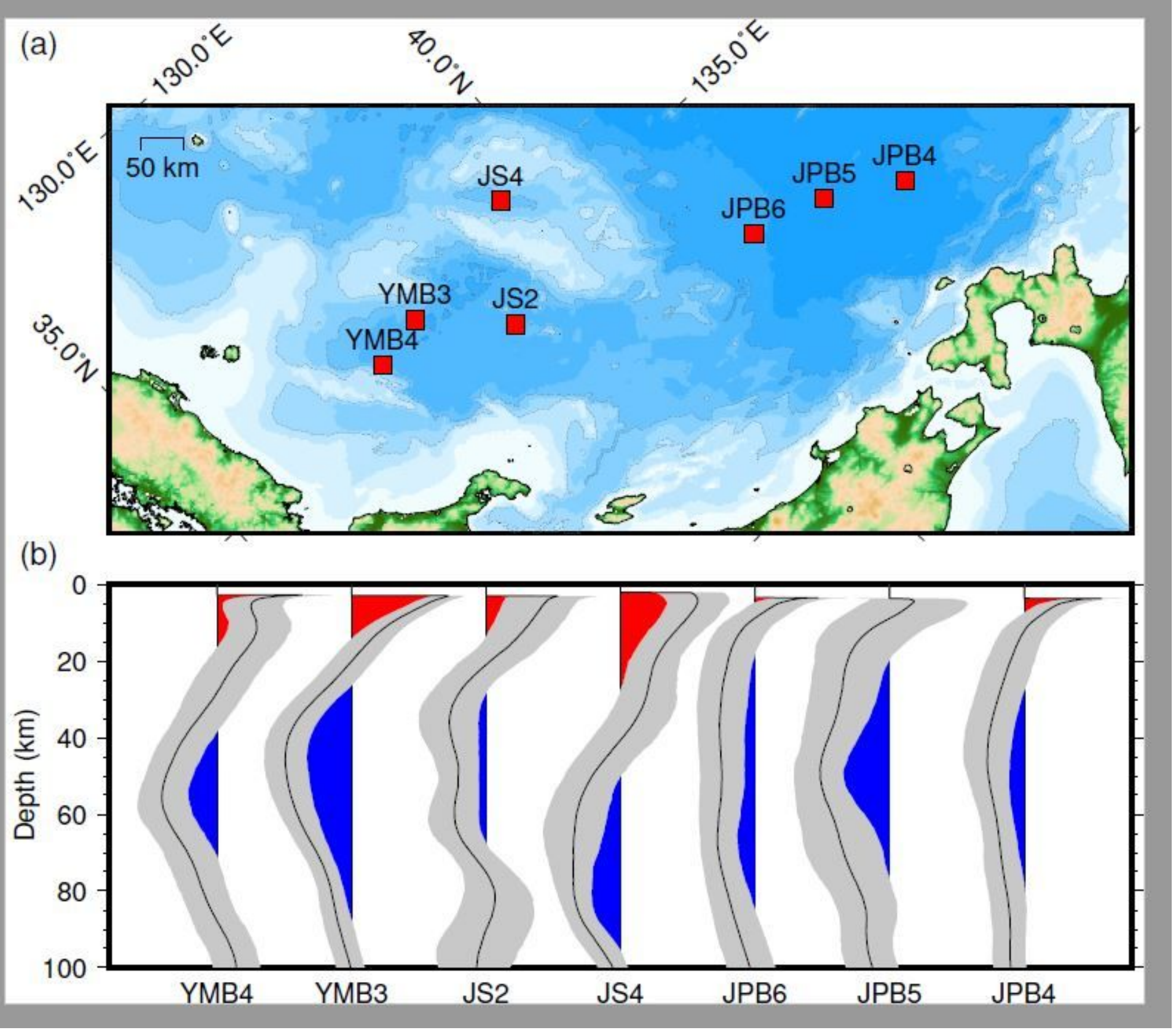

Figure 10

Time-to-depth converted and stacked S-receiver functions (S-RFs) for each station. (a) Stations locations (red squares). (b) The depth-converted, stacked S-RFs. Positive and negative amplitudes are shaded in red and blue, respectively. The gray shade represents the $95 \%$ confidence interval from bootstrap resampling 1000 times. Note: The designations employed and the presentation of the material on this map do not imply the expression of any opinion whatsoever on the part of Research Square concerning the legal status of any country, territory, city or area or of its authorities, or concerning the delimitation of its frontiers or boundaries. This map has been provided by the authors. 




\section{Figure 11}

Comparison to surface wave tomography model. (a) Seafloor topography profile. (b) Cross section of Swave velocity model estimated by surface wave tomography (Yoshizawa et al. 2010). The shallow portion ( $<30 \mathrm{~km}$ depth) is masked by the gray shade because of insufficient resolution with long-period surface waves. Blue horizons roughly indicate the lithosphere-asthenosphere boundary inferred from the inversion. Red squares denote station locations. (c) Profile location (red line) and station locations (red squares). 


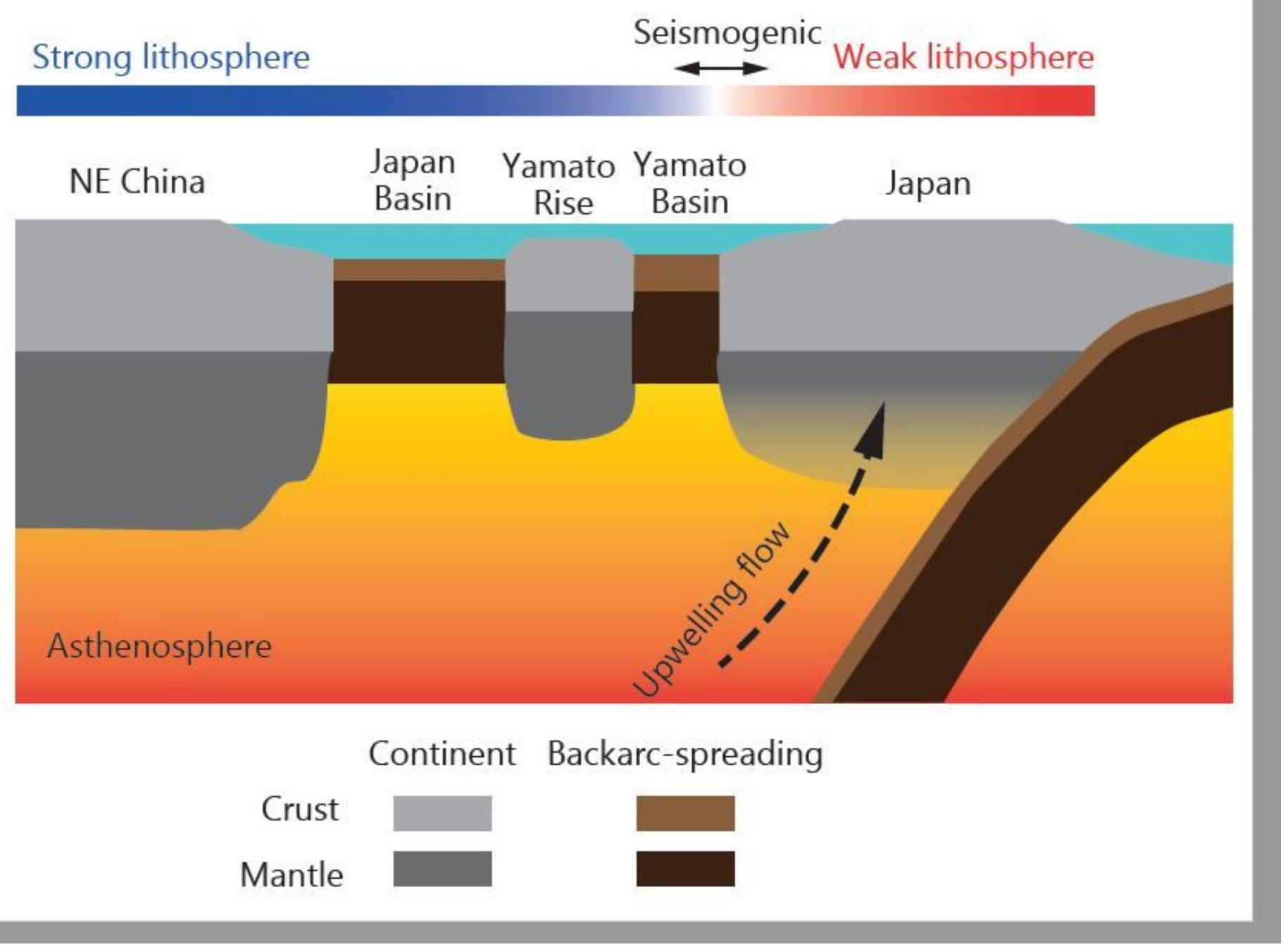

\section{Figure 12}

Schematic illustration of the lithosphere-asthenosphere system across northeastern Japan, the Sea of Japan, and northeastern China.

\section{Supplementary Files}

This is a list of supplementary files associated with this preprint. Click to download.

- Appendix1.docx

- graphicalabst.png 